\title{
Pelatihan Pembuatan Bahan Ajar Speaking Berbasis Rekayasa Faktor Kognitif (Task Complexity) bagi Guru-Guru SMA/SMK Di Kabupaten Pringsewu
}

\author{
Mahpul $^{1 \star}$, Bambang Setiyadi², Muhammad Sukirlan ${ }^{3}$, Gede Eka Putrawan $^{4}$ \\ English Education, Lampung University, Bandar Lampung, 35145, Lampung, Indonesia
}

\begin{abstract}
.
Task complexity-based learning approaches have been widely adopted in countries especially where English is a foreign language, Chinese, Japanese, Arabic, Iranian, and Korean. However, most English teachers do not yet understand the method of learning English based on task complexity so they lack confidence in applying the method. Therefore, this community service activity aims to increase insight and knowledge about the development / creation of a speaking learning model based on cognitive factor engineering (task complexity). This activity will target English teachers at high school / vocational school in Pringsewu Regency and is expected to improve their professionalism to improve the quality of the English learning process, especially speaking. This activity will be carried out with lecture methods, discussions, practices, and simulations that will begin with a pre-test and end with a post-test. Based on initial and final abilities, there are quite real differences before and after the training is done. To that end, this training has been able to improve the insight and Manufacture of Teaching Materials Based on Cognitive Factor Engineering (Task Complexity). Some participants showed that the enthusiasm and belief of the participants that the Manufacture of Speaking Teaching Materials Based on Cognitive Factor Engineering (Task Complexity) has a positive impact to develop students' ability to master their English learning in the classroom.
\end{abstract}

Keywords.

task complexity, community service, task-based language teaching, English, training, workshops

\section{PENDAHULUAN}

Model pembelajaran speaking (berbicara) berdasarkan rekayasa faktor kognitif (task complexity) sudah diadopsi secara luas di berbagai negara terutama di mana bahasa Inggris sebagai bahasa asing, China, Jepang, Arab, Iran, dan Korea [1-9].

\section{* Corresponding author: mahpul.1965@gmail.com}

Received 10 October 2021; Received in revised form 19 October 2021; Accepted 20 October 2021 
Model pembelajaran speaking (berbicara) berdasarkan rekayasa faktor kognitif (task complexity) merupakan pendekatan pembelajaran bahasa yang menekankan penggunaan bahasa sebagai alat komunikasi dalam kehidupan nyata (real-life activities). Model pembelajaran speaking (berbicara) berdasarkan rekayasa faktor kognitif (task complexity) lebih menitikberatkan pada proses berbahasa (Uses) daripada belajar ilmu bahasa (Usage), sehingga pembelajar menjadi lebih aktif dalam proses pembelajaran berbahasa $[10,11]$.

Beberapa penelitian terkait model pembelajaran speaking (berbicara) berdasarkan rekayasa faktor kognitif (task complexity) di Indonesia menunjukan bahwa model pembelajaran speaking (berbicara) berdasarkan rekayasa faktor kognitif (task complexity) memfasilitasi siswa terlibat akktif dalam proses pembelajaran bahasa sehingga mampu meningkatkan kemampuan siswa berbicara (speaking) dalam bahasa Inggris [12-15].

Namun, sebagian besar guru bahasa Inggris belum memahami model pembelajaran speaking (berbicara) berdasarkan rekayasa faktor kognitif (task complexity) sehingga mereka kurang percaya diri dalam menerapkan metode tersebut [16]. Akibatnya para guru bahasa Inggris tetap menerapkan model/pendekatan pembelajaran bahasa Inggris yang mengutamakan penguasaan aspek bahasa (forms) yang terbukti kurang mampu memfasilitasi siswa dalam meningkatan kemampuan berbicara dalam bahasa Inggris. Hal ini mengindikasikan perlu adanya perubahan paradigma metode pembelajaran bahasa Inggris khususnya keterampilan berbicara (speaking).

model pembelajaran speaking (berbicara) berdasarkan rekayasa faktor kognitif (task complexity) adalah bahan ajar/materi sangat terkait dengan rekayasa faktor kognitif yang sering disebut the Cognition Hypothesis [,4-6,17-19]. Menurut the Cognition Hypothesis, faktor kognitif bisa direkayasa untuk meningkatkan kemampuan siswa/pembelajar dalam berbahasa (berbicara).

Hasil dari kegiatan pengabdian kepada masyarakat ini adalah untuk: 1) Meningkatkan wawasan dan pengetahuan tentang pengembangan/pembuatan model pembelajaran speaking (berbicara) berdasarkan rekayasa faktor kognitif (task complexity) bagi guru-guru bahasa Inggris di SMA, dan SMK di Kabupaten Pringsewu. 2) Meningkatkan profesionalisme bagi guru-guru bahasa Inggris SMA, dan SMK di Kabupaten Pringsewu agar mampu memperbaiki kualitas proses pembelajaran Bahasa Inggris khusunya speaking sehingga kemampuan berbicara para siswa SMA, dan SMK akan meningkat. 3) Memberikan ketrampilan pengembangan dan penggunaan model pembelajaran speaking (berbicara) berbasis rekayasa faktor kognitif bagi guru guru SMA dan SMK di kabupaten Pringsewu

\section{SOLUSI DAN TARGET}

Berdasarkan analisis situasi dan permasalahan yang dihadapi oleh masyarakat mitra seperti di atas, maka ada solusi sistematis yang ditawarkan untuk mengatasi masalah yang dihadapi. Solusi yang ditawarkan yaitu melalui kegiatan pelatihan model pembelajaran berbasis task bagi guru-guru bahasa Inggris di SMA/SMK untuk meningkatkan kemampuan berbicara (speaking) para siswa dalam bahasa Inggris.

Tujuan pembelajaran berbasis task menekankan tidak hanya pada penguasaan makna 
(meaning) tetapi juga pada penguasaan aspek linguistik (forms) walaupun makna dianggap lebih utama dibandingkan forms [3,20-24]. Fokus pada makna artinya siswa dilatih untuk memahami dan mempraktekan duamakna pragmatik dan semantik dalam berkomunikasi karena kedua makna tersebut diyakini memiliki peran yang sangat penting dalam sebuah komunikasi oleh karena itu proses pembelajaran bahasa sebaiknya lebih difokuskan pada penguasaan kedua aspek makana tersebut [21]. Menurut Van de Branden et al., (2009), melalui pembelajaran berbasis task siswa difasiliatsi dengan aktifitas yang mampu membuat siswa terlibat secara aktif dalam proses komunikasi karena siswa "dimanipulasi" dengan aktifitas yang merefleksikan kehidupan nyata dengan fokus kepada makna (meaning) dan linguistik (forms) yang merupakan faktor penting dalam proses pembelajaran bahasa (Inggris) [11].

Beberapa tahun terakhir, model pembelajaran berbasis task dikembangkan berdasarkan the Cognition Hypothesis yang digagas oleh $[25,18,4,5,26,6,19]$. The Cognition Hypothesis menjelaskan pentingnya peran kognitif dalam meningkatkan kemampuan siswa/pembelajar dalam berbahasa. Hal ini pernah terjadi dalam pembelajaran Bahasa inggris di Taiwan, Wang (2010) meskipun bertahun-tahun pengajaran bahasa Inggris di sekolah, ditemukan bahwa banyak siswa Taiwan gagal menggunakan bahasa target secara kompeten untuk komunikasi yang sebenarnya [27]. Hal ini tentu pada pembelajaran Bahasa inggris di SMA/SMK Kabupaten pringsewu harus mampu menciptakan pembelajaran yang menarik.

\section{PELAKSANAAN}

Pelatihan pengembangan metode pembelajaran speaking berbasis task complexity dilaksanakan menggunakan metode:

1. Ceramah tentang prinsip-prinsip pembelajaran speaking berbasis rekayasa faktor kogntif (task complexity) khususnya peran faktor kognitif serta penjelasan tentang kaidah pengembangan model pembelajaran speaking berbasis task diikuti dengan tanya jawab dan diskusi.

2. Pemberian contoh dan diskusipengembangan model pembelajaran speaking berbasis rekayasa faktor kognitif (task complexity).

3. Pemberian tugas untuk mendesain model pembelaj aran berbasis task dengan dibimbing oleh para instruktur.

4. Praktek simulasi model pembelajaran speaking berbasis task. Instruktur memberikan masukan atas kelemahan dan kelebihan model pembelajaran.

Beberapa kegitaan akan dilakukakn untuk mengetahui efektifitas hasil pelatihan pengembangan model pembelajaran speaking berbasis task, sebagai berikut:

\section{Pre-Test}

Pretest berupa questionnaire (close dan open-ended questions). Para guru diminta untuk menjawab pertanyaan terkait pengetahuan mereka tentang pendekatan/model pembelajaran speaking berbasis rekayasa faktor kognitif (task complexity). Hal ini dilakukan untuk mengetahui kemampuan awal para guru tentang model Pembuatan Bahan Ajar Speaking Berbasis Rekayasa Faktor Kognitif (Task Complexity) secara umum maupun 
terkait khusus pembelajaran speaking.

\section{Observasi}

Observasi akan dilakukan pada saat pelatihan berlangsung untuk mengetahui kesulitan/kendala yang dihadapai para guru dalam mendesain dan mengimplementasikan model pembelajaran yang dibuat.

\section{Post-Test}

Dalam post-test para peserta tidak hanya diberi questionnaire (close dan open-ended questions) seperti dalam pre-test, tetapi mereka diberi tiugas mendesain model pembelajaran berdasarkan rekayasa faktor kognitif.

\section{HASIL DAN PEMBAHASAN}

Kegiatan pengabdian kepada masyarakat yang berjudul "Pelatihan Pembuatan Bahan Ajar Speaking Berbasis Rekayasa Faktor Kognitif (Task Complexity) bagi Guru-Guru SMA/SMK Di Kabupaten Pringsewu" ini dilaksanakan berdasarkan studi pendahuluan melalui wawancara dengan guru-guru bahasa Inggris. Sebagian besar guru bahasa Inggris tersebut belum memahami model Pembuatan Bahan Ajar Speaking Berbasis Rekayasa Faktor Kognitif (Task Complexity) sehingga mereka kurang percaya diri dalam menerapkan metode tersebut [16], termasuk para guru Bahasa Inggris di Kabupaten Pringsewu. Akibatnya mereka tetap menggunakan model/pendekatan pembelajaran bahasa Inggris yang lebih mengutamakan penguasaan aspek bahasa (forms) sehingga terbukti kurang efektif dalam pembelajaran Bahasa inggris karena tidak dapat memfasilitasi siswa. Kejadian ini pernah di jelaskan Wang (2010) pada pembelajaran bahwa pendidikan bahasa Inggris di Taiwan lebih menekankan pada penilaian tertulis daripada kemampuan komunikasi [27]. Metode pengajaran bahasa Inggris yang khas adalah berbasis bentuk dan berbasis teks, dan banyak guru mengadopsi Metode Terjemahan Tata Bahasa atau Metode Audiolingual dalam pengajaran mereka [27]. Untuk menjadi perhatian bersama sehingga pelatihan ini guna mendapatkan pembelajaran Bahasa inggris yang menarik dan dapat di terima oleh siswa.

Demi meningkatkan pengetahuan dan wawasan bagi guru Bahasa inggris, beberapa langkah diambil oleh tim pengabdian yang meliputi: (1) membuat proposal pengabdian kepada masyarakat yang ditujukan kepada Universitas Lampung, (2) melakukan koordinasi dengan mitra pengabdian, (3) menyusun materi pelatihan, dan (4) melaksanakan kegiatan pelatihan.

\section{Peserta Pelatihan}

Pengabdian kepada masyarakat yang dilaksanakan di Kabupaten Pringsewu ini diikuti oleh 31 peserta dengan durasi waktu pelatihan selama 32 jam. Daftar peserta pelatihan adalah sebagai berikut.

Tabel 1. Nama peserta pelatihan

No. Nama Peserta Asal Sekolah




\begin{tabular}{|c|c|c|}
\hline 1 & Elmi Yuli Yanti, S.Pd & SMA N2 PRINGSEWU \\
\hline 2 & Listinasari, M.Pd & SMK Muhammadiyah Pagelaran \\
\hline 3 & Bambang Prasetio & SMAN 1 Pagelaran \\
\hline 4 & Sumiyati,S.Pd. & SMKN 1 Gadingrejo Pringsewu \\
\hline 5 & Zuni Purnawati, S.Pd & SMAN 1 ADILUWIH \\
\hline 6 & Eka Fitriana, S. Pd. & SMA N 1 SUKOHARJO \\
\hline 7 & Nazal Fisabela Velayati & SMAN 1 PRINGSEWU \\
\hline 8 & Kiki Anggraeni & Smk yasmida \\
\hline 9 & Wahyu Widiastuti, S.Pd & Universitas Lampung \\
\hline 10 & Henudin, S. Pd & SMA N 1 Ambarawa Pringsewu \\
\hline 11 & Desi Kurniawati & SMK Yasmida Ambarawa \\
\hline 12 & Sri Nur Hidayh, S.Pd & SMK PGRI 2 Pringsewu \\
\hline 13 & Asih Indah Budiyani & SMA IT Insan Mulia Boarding School \\
\hline 14 & Nuraeni & SMK Yadika Pagelaran \\
\hline 15 & Siti Rohmawati & SMA Muhammadiyah Gadingrejo \\
\hline 16 & Lilis Suhaya & SMKS MA'ARIF BANYUMAS \\
\hline 17 & Mema Sopiyana, M.Pd. & SMA N 1 PRINGSEWU \\
\hline 18 & Dra. Nur Khasanah,M.Pd & SMAN 1 PRINGSEWU \\
\hline 19 & Muharawan & SMA N 1 Ambarawa \\
\hline 20 & Sugiarti & SMKN 1 GADINGREJO \\
\hline 21 & G. Fida Artika & SMA Yasmida Ambarawa \\
\hline 22 & Fera Cantra Kusumajati & sma negeri 1 pagelaran \\
\hline 23 & Dra. HUSTIATI & SMK Muhammadiyah Ambarawa \\
\hline 24 & Nur Asriyanti Fatimah & SMAN 2 PRINGSEWU \\
\hline 25 & Fradia Zhulfatunnisa & SMAN 2 PRINGSEWU \\
\hline 26 & Mutiara Kusuma Dewi & SMK KARYA BHAKTI \\
\hline 27 & Fita Sari & SMK YAPEMI PAGELARAN \\
\hline 28 & lis Widayati & Sma $n 1$ adiluwih \\
\hline 29 & Anna Merita Sari & SMK Yadika Pagelaran \\
\hline 30 & Dwi Ratnawati, S.Pd & SMA 17 Pagelaran \\
\hline 31 & Puji Purwaningsih,S.Pd & SMK Widya Yahya Gadingrejo \\
\hline
\end{tabular}

Selama proses pelatihan berlangsung, para peserta tampak antusias menyimak materi yang disampaikan oleh para narasumber yang dilakukan secara daring yang dengan penuh kesabaran memberikan materi kepada peserta dengan diselingi humor membuat kelas terasa semakin nyaman untuk belajar. Tanya jawab dan diskusi terjadi manakala ada bagian yang dirasa tidak jelas dan kurang dipahami oleh para peserta. Para peserta diberi kebebasan untuk menyela untuk meminta penjelasan kepada narasumber tentang materi salah satunya adalah berkaitan dengan Menjadi guru harus memahami karakter siswa dan jadilah guru yang baik. Hal tersebut bertujuan untuk proses pelatihan menjadi lebih efektif, interaktif, dan efisien.

Peserta nampak lebih antusias mendengarkan materi narasumber ketika sesi praktik dan simulasi yang diselingi canda dan tawa sehingga membuat suasana interaktif dan 
menyenangkan. Melihat proses tersebut, dapat dikatakan bahwa para peserta memiliki semangat dan keingintahuan yang tinggi untuk menerapakan model Pembuatan Bahan Ajar Speaking Berbasis Rekayasa Faktor Kognitif (Task Complexity).

\section{HASIL}

Para guru di awal dan akhir pelatihan diberikan angket untuk melihat pemahaman mereka terhadap konsep Pembuatan Bahan Ajar Speaking Berbasis Rekayasa Faktor Kognitif (Task Complexity). hasil pelatihan pada sesi pre-test dan post-test guru Bahasa inggris dapat di lihat pada gambar di bawah ini.

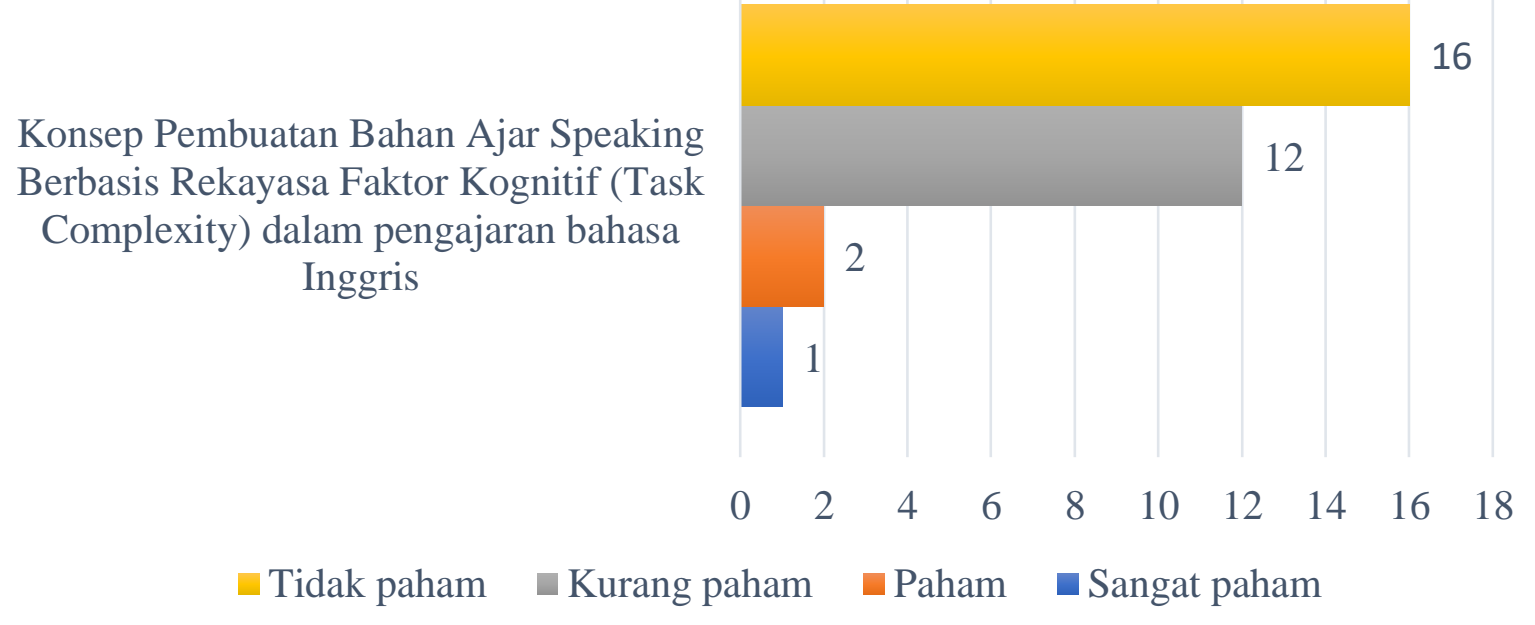

Gambar 1. Hasil tes awal (pre-test) sebelum kegiatan dimulai

Gambar 1. di atas menunjukkan bahwa sebagian besar peserta (16) tidak memahami konsep Pembuatan Bahan Ajar Speaking Berbasis Rekayasa Faktor Kognitif (Task Complexity) dalam pengajaran bahasa Inggris dan 2 peserta kurang memahami. Peserta yang sangat memahami 1 peserta dan memahami 2 peserta. 
Konsep Pembuatan Bahan Ajar Speaking Berbasis Rekayasa Faktor Kognitif (Task Complexity) dalam pengajaran bahasa Inggris

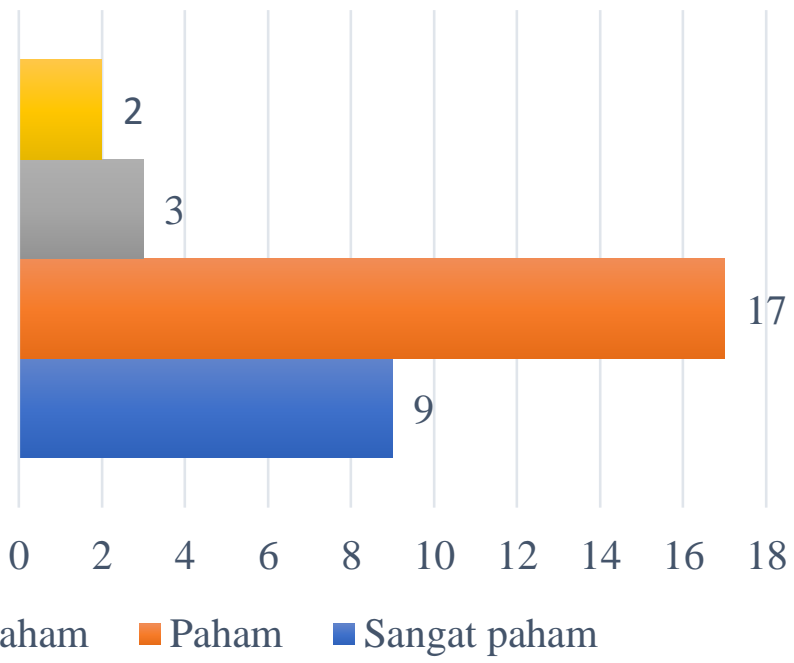

Gambar 2. Hasil tes akhir (post-test) setelah kegiatan

Gambar 2. di atas menunjukkan bahwa sebagian besar peserta sangat memahami sebanyak 9 peserta dan memahami konsep Pembuatan Bahan Ajar Speaking Berbasis Rekayasa Faktor Kognitif (Task Complexity) setelah mengikuti pelatihan sebanyak 17 peserta. Masih terdapat 3 peserta pelatihan yang masih kurang memahami konsep ini dan diikuti oleh 2 peserta yang masih tidak memahami konsep ini. Namun, sebagian besar dari peserta telah 'sangat memahami' dan 'memahami' konsep ini dengan baik. Dengan penjelasan tersebut guru nantinya mampu menciptakan bahan ajar yang kognitif Meningkatnya minat pada pendekatan pembelajaran yang berpusat pada siswa di antara para pendidik Bahasa telah menyebabkan banyak penelitian menyelidiki strategi pembelajaran bahasa individu (LLS) dan hubungannya dengan prestasi dalam belajar bahasa kedua/asing [28]. Studi telah menunjukkan dukungan untuk strategi pembelajaran bahasa yang diterapkan secara tepat pada pencapaian bahasa kedua dalam Speaking Berbasis Rekayasa Faktor Kognitif (Task Complexity) [29-38].

Selanjutnya, peserta diminta membuat ataupun meningkatkan modul ajar speaking berbasis Pembuatan Bahan Ajar Speaking Berbasis Rekayasa Faktor Kognitif (Task Complexity) cocok dengan modul yang sudah di informasikan oleh para narasumber kemudian mendapatkan penilain yang sangat baik ketika dilakukan pengecekan. Aspekaspek Pembuatan Bahan Ajar Speaking Berbasis Rekayasa Faktor Kognitif (Task Complexity) yang dinilai dari materi ajar yang dikembangkan oleh para peserta pelatihan adalah task yang terdiri dari beberapa stages dan aspek: 1) pre-task; 2) during task; 3) post task; dan 4) faktor kognitif (resource-directing dan resource despersing).

Sebagian besar peserta mampu memahami konsep Pembuatan Bahan Ajar Speaking Berbasis Rekayasa Faktor Kognitif (Task Complexity) dan mengembangkan materi ajar berdasarkan konsep Pembuatan Bahan Ajar Speaking Berbasis Rekayasa Faktor Kognitif (Task Complexity) ini. Hanya sebagian kecil yang kurang dan belum memahami pengembangan materi ajar berdasarkan konsep ini. Ini dapat dilihat dari rerata pengembangan materi ajar yang mereka lakukan nantinya dalam kelas. Menurut Widagdo (2018), proses pembelajaran di kelas haruslah berkualitas, yang ditandai oleh tiga unsur: (1) 
tingkat partisipasi dan jenis kegiatan belajar yang dihayati oleh mahasiswa, (2) peran dosen dalam proses belajar mengajar, dan (3) suasana proses belajar [39].

Berikut adalah kutipan wawancara informal para peserta ketika diminta menyampaikan hasil dari pelatihan Pembuatan Bahan Ajar Speaking Berbasis Rekayasa Faktor Kognitif (Task Complexity).

- Semoga agenda seperti ini akan sering dilaksanakan karena materi yang sangat luar biasa (Peserta 7)

- Pembuatan Bahan Ajar Speaking Berbasis Rekayasa Faktor Kognitif (Task Complexity) akan membuat siswa merasa santai dan nyaman untuk membantu mereka menggunakan bahasa sasaran dengan tepat (Peserta 12)

- sudah baik dan sangat bermanfat bagi kami guru bahasa inggris di masa pandemi. (Peserta 17)

- Materinya sesuai dengan konteks dunia nyata yang terjadi sekarang. Menarik! (Peserta 21)

- Pembuatan Bahan Ajar Speaking Berbasis Rekayasa Faktor Kognitif (Task Complexity) bisa sekaligus untuk melakukan manajemen kelas dengan menjadikan Bahasa inggris mudah di pahami meskipun persiapannya perlu waktu lebih namun tidak masalah (Peserta 23)

Hasil wawancara tersebut menunjukkan bahwa para peserta akan mengimplementasikan konsep Pembuatan Bahan Ajar Speaking Berbasis Rekayasa Faktor Kognitif (Task Complexity) dalam kelas bahasa Inggris mereka. Kemampuan berbicara dilihat sebagai standar keberhasilan siswa dalam pembelajaran bahasa mereka. Keberhasilan yang dimaksud adalah kemampuan untuk menggunakan Bahasa Inggris secara tepat dan fasih untuk berkomunikasi dengan orang lain, jadi bisa dikatakan ketepatan dan kefasihan dalam berbahasa sangat penting [40]. Membuat Bahan Ajar Berbicara Berdasarkan Rekayasa Faktor Kognitif (Task Complexity) di kelas bahasa Inggris menemukan bahwa meningkatnya kompleksitas tugas sehubungan dengan? Dimensi Hereand-Now meningkatkan akurasi, kompleksitas, dan kelancaran produksi bahasa tulis [41].

\section{PEMBAHASAN}

Tujuan dari kegiatan ini adalah untuk: (1) meningkatkan wawasan dan pengetahuan tentang pengembangan/pembuatan model Pembuatan Bahan Ajar Speaking Berbasis Rekayasa Faktor Kognitif (Task Complexity) bagi guru-guru bahasa Inggris di Kabupaten Pringsewu; dan (2) memberikan keterampilan pengembangan dan penggunaan model pembelajaran speaking (berbicara) berbasis rekayasa faktor kognitif bagi guru guru di kabupaten Pringsewu.

Hasil angket yang telah di isi oleh peserta bedasarkan kemampuan awal dan akhir, terdapat perbedaan yang cukup nyata sebelum dan setelah pelatihan dilakukan. Untuk itu, pelatihan ini telah mampu meningkatkan wawasan dan Pembuatan Bahan Ajar Speaking Berbasis Rekayasa Faktor Kognitif (Task Complexity). Selain itu, berdasarkan yang dilakukan pada penilaian materi ajar dikembangkan oleh para peserta pelatihan, dapat dilihat bahwa mereka telah mampu memahami dan mengimplemtasikan konsep Pembuatan 
Bahan Ajar Speaking Berbasis Rekayasa Faktor Kognitif (Task Complexity) rekayasa kognitif dalam bentuk materi ajar. Sehingga bisa dikatakan para peserta telah memiliki keterampilan untuk mengembangkan materi ajar berbasis Pembuatan Bahan Ajar Speaking Berbasis Rekayasa Faktor Kognitif (Task Complexity) rekayasa faktor kognitif. Ini juga merupakan satu-satunya studi yang menguji efek kompleksitas tugas pada kompleksitas dan akurasi penulisan bahasa kedua, memperluas diskusi tentang kompleksitas dalam penulisan bahasa kedua untuk dipelajari [1]. Saat ini, pengajaran berbicara Bahasa Inggris sebagai bahasa kedua atau bahasa asing dalam mata pelajaran bahasa Inggris di sekolah sangatlah penting. Ada banyak siswa atau orang yang ingin belajar bahasa Inggris untuk tujuan komunikatif [40].

Bahan penguat dilakukan wawancara kepada beberapa peserta, antusiasme dan keyakinan para peserta bahwa Pembuatan Bahan Ajar Speaking Berbasis Rekayasa Faktor Kognitif (Task Complexity) memiliki dampak yang membawa kepada arah positif untuk mengembangkan kemampuan siswa dalam menguasai pembelajaran Bahasa inggris mereka di kelas. Hal ini berarti bahwa mereka percaya model ini akan membantu meningkatkan kemampuan komunikasi dan interaksi siswa mereka [42], karena sebagian besar para peserta telah memahami konsep Pembuatan Bahan Ajar Speaking Berbasis Rekayasa Faktor Kognitif (Task Complexity) berdasarkan rekayasa faktor kognitif ini [43].

\section{KESIMPULAN}

Kegiatan pengabdian kepada masyarakat ini telah mencapai tujuan yaitu: (1) meningkatkan wawasan dan pengetahuan tentang pengembangan/pembuatan model pembelajaran speaking (berbicara) berdasarkan rekayasa faktor kognitif (task complexity) bagi guru-guru bahasa Inggris di Kabupaten Pringsewu; dan (2) memberikan ketrampilan pengembangan dan penggunaan model pembelajaran speaking (berbicara) berbasis rekayasa faktor kognitif bagi guru guru di kabupaten Pringsewu. Hal ini dapat dilihat dari hasil pre-test dan post-test. Hasil penilaian lembar kerja dan wawancara tak terstruktur dengan para peserta juga menunjukkan bahwa sebagian besar peserta mampu memahami konsep Pembuatan Bahan Ajar Speaking Berbasis Rekayasa Faktor Kognitif (Task Complexity) dan mengembangkan materi ajar berdasarkan konsep pembelajaran speaking dengan communicative approach Pembuatan Bahan Ajar Speaking Berbasis Rekayasa Faktor Kognitif (Task Complexity) rekayasa faktor kognitif. Dengan demikian, dapat dikatakan bahwa peserta merasakan manfaat setelah berpartisipasi dalam kegiatan pelatihan ini.

Meskipun kegiatan ini telah usai dilaksanakan, peserta diharapkan terus berusaha secara mandiri mengimplementasikan pengajaran bahasa Inggris dengan konsep Pembuatan Bahan Ajar Speaking Berbasis Rekayasa Faktor Kognitif (Task Complexity) rekayasa faktor kognitif ini untuk membantu siswa meningkatkan kemampuan komunikasinya dalam bahasa Inggris sehingga pengajaran bahasa Inggris tidak hanya didasarkan pada aspek struktur bahasa (forms). Pelatihan sejenis seperti ini masih sangat perlu dilakukan di masa mendatang agar berkelanjutan dan berdampak lebih nyata. 


\section{UCAPAN TERIMA KASIH}

Pada kesempatan yang berharga ini, tim pengabdian mengucapkan terima kasih kepada LPPM Universitas Lampung yang telah mendanai kegiatan pengabdian kepada masyarakat ini melalui Hibah Pengabdian Kepada Masyarakat Skema Unggulan

\section{DAFTAR PUSTAKA}

[1] Adams, R., Nik Mohd Alwi, N. A., \& Newton, J. (2015). Task complexity effects on the complexity and accuracy of writing via text chat. Journal of Second Language Writing, 29, 64-81. https://doi.org/10.1016/j.js/w.2015.06.002

[2] Ahmadian, J. M., \& Tavakoli, M. (2010). The effects of simultaneous use of careful online planning time and task repetition on accuracy, complexity, and fluency in EFL learners' oral production. Language Teaching Research, 15(1), 35-59.

[3] Nunan, D. (2004). Task-based language teaching. Cambridge University Press.

[4] Robinson, P. (2003). The cognitive hypothesis, task design, and adult task-based language learning. Second Language Studies, 21(2), 45-105.

[5] Robinson, P. (2005a). Cognitive complexity and task sequencing: studies in a componential framework for second language task design. Review of Applied Linguistics in Language Teaching, 43, 1-32.

[6] Robinson, P. (2007). Criteria for classifying and sequencing pedagogic tasks. In M. P. Garcia Mayo (Ed.), Investigating tasks in formal language teaching: SLA (pp. 7-27). Multilingual Matters.

[7] Saeedi, M., Ketabi, S., \& Kazerooni, S. R. (2012). The impacts of manipulating task complexity on EFL learners performance. GemaTM Online Journal of Language Studies, 12(4), 1057-1075.

[8] Yuan, F., \& Ellis, R. (2003). effect of pre-task planning and on-line planning on fluency, complexity, and accuracy in L2 monologic oral production. Applied Linguistics, 24, 1-27.

[9] Yuan, F., \& Ellis, R. (2005). The effect of careful within-task planning on oral production and written task performance. In R Ellis (Ed.), Language learning \& language teaching: planning and task performance in second language (pp. 167-192). John Benjamins Publishing Company.

[10] Samuda, V., \& Bygate, M. (2008). Tasks in second language learning (Palgrave). Macmillan.

[11] Van de Branden, K., Bygate, M., \& M, N. J. (2009). Tasked-based language teaching: introducing the reader. John Benjamins Publishing Company.

[12] Agustina, V. (2017). The use of task complexity in spoken data by the second grade of SMAN Padeang Cermin. Lampung University.

[13] Mahpul. (2018). The effect of task complexity in dialogic oral production by Indonesian. The Asian EFL Journal, 20(8), 20-35.

[14] Mahpul, \& Nurweni, A. (2016). Pengembangan model pembelajaran berbasis task untuk meningkatkan kemampuan berbicara mahasiswa. Penelitian Hibah Dikti.

[15] Nurcahyani, R. (2009). The effect of task complexity on spoken production by the eighth gade students of SMPN 37 Bandarlampung. Lampung University.

[16] Luciana. (2005). Negotiation of meaning in communicative tasks. Indonesian Journal of English Language Teaching, 1(1), 45-56.

[17] Robinson, P. (2001a). Task complexity, cognitive resources, and syllabus design: a a triadic framework for examining task influences on SLA (Robinson,). Cambridge University Press.

[18] Robinson, P. (2001b). Task complexity, cognitive resources, and syllabus design: a triadic framework for examining task influences on SLA. In Robinson, P. (Ed.), Cognition and Second Language Instruction, 287-318.

[19] Robinson, P. (2011). Task-based language learning: a review of issues. Language Learning, Supplement, 1-36.

[20] Ellis, R. (2003). Task-based language teaching and learning. Oxford University Press.

[21] Ellis, R. (2005). Instructed language learning and task-based teaching. In E. Hinkel (Ed.), Handbook of 
research in second language teaching and learning (pp. 713-728). Routledge.

[22] Ellis, R. (2009). Corrective Feedback and Teacher Development. L2 Journal, 1(1), 2-18. https://doi.org/10.5070/l2.v1i1.9054

[23] Skehan, P. (1996). A Framework for the implementation of task-based instruction. Applied Linguistics, 17, 38-62.

[24] Skehan, P. (1998). A cognitive approach to language learning. 336. https://books.google.com/books?hl=en\&lr=\&id=Yzdl3pW0Yf4C\&oi=fnd\&pg=PP6\&dq=skehan\&ots=U8e4 G21dyD\&sig=8hTp0CuTfhfZRudsWIZu56IMKjo

[25] Robinson, P. (2001c). Task complexity, task difficulty, and task production: Exploring interactions in a componential framework. Applied Linguistics, 22(1), 27-57.

[26] Robinson, P. (2005b). The cognitive hypothesis, task design, and adult task-based language learning.Second Language Studies. Second Language Studies, 21(2), 45-105.

[27] Wang, Y.-H. (2010). Using Communicative Language Games in Teaching and Learning English in Taiwanese Primary Schools. Journal of Engineering Technology and Education, 7(1), 126-142.

[28] Hong-Nam, K., \& Leavell, A. G. (2006). Language learning strategy use of ESL students in an intensive English learning context. System, 34(3), 399-415. https://doi.org/10.1016/j.system.2006.02.002

[29] Bremner, S. (n.d.). Language learning strategies and language proficiency: Investigating the relationship in Hong Kong. Asian Pacific Journal of Language in Education, 1(2), 490-514.

[30] Green, J., \& Oxford, R. L. (1985). A closer look at learning strategies, L2 proficiency, and gender. TESOL Quarterly, 29(2), 261-297.

[31] Griffiths, C., \& Parr, J. M. (2001). Language-learning strategies: Theory and perception. ELT Journal, 53(3), 247-254.

[32] Mansanares, L. K., \& Russo, R. P. (1985). Language learning: Learning strategies used by beginning and intermediate ESL students. Language Learning, 35(1), 21-42.

[33] Oxford, R. L. (1990). Language Learning Strategies: What Every Teacher Should Know. Heinle and Heinle.

[34] Oxford, R. L., \& Ehrman, M. (1995). Adult's language learning strategies in an intensive foreign language program in the United States. System, 23(3), 359-386.

[35] Oxford, R. L., \& Nyikos, M. (1989). Variables affecting choice of language learning strategies by university students. The Modern Language Journal, 73(3), 291-300.

[36] Park, G. P. (1997). Language learning strategies and English proficiency in Korean University. Foreign Language Annals, 30(2), 211-221.

[37] Politzer, R. (1983). An exploratory study of self-reported language learning behaviors and their relation to achievement. Studies in Second Language Acquisition, 6, 54-65.

[38] Wharton, G. (2000). Language learning strategy use of bilingual foreign language learners in Singapore. Language Learning, 50(2), 203-243.

[39] Widagdo, A. (2018). Arif Widagdo Jurusan PGSD, Fakultas Ilmu Pendidikan Universitas Negeri Semarang A. PENDAHULUAN Mahasiswa sebagai penerus pembangunan nasional harus dibekali dengan ilmu dan keterampilan yang dapat membuat mereka mampu bersaing di era modern saat ini, s. MAGISTRA -, 9(2), 64-87.

[40] Roosdianna, F. F., Munir, A., \& Anam, S. (2018). Teachers' Strategies to Improve Accuracy and Fluency in Speaking. Proceeding Icon-ELite, 1(1), 144-148.

[41] Ishikawa, T. (2007). The effect of manipulating task complexity along the (+/-here-and -now) dimension on L2 written narrative discourse. In M. P. Garcia Mayo (Ed.), Investigating tasks in formal language teaching: SLA (pp. 136-156). Multilingual Matters.

[42] Jeon, I.-J., \& Hahn, J. (2006). Exploring EFL teachers' perceptions of task-based language teaching: A case study of Korean secondary school classroom Practice. Asian EFL Journal, 8(1), 1-247.

[43] Abdel-Hadi, A. (2012). Culture, Quality of Life, Globalization and Beyond. Procedia - Social and Behavioral Sciences, 50(July), 11-19. https://doi.org/10.1016/j.sbspro.2012.08.011 
